\title{
GESTÃO DE COLEÇÕES PARA BIBLIOTECAS ESPECIALIZADAS: Uma perspectiva teórica para o planejamento de recursos informacionais
}

\author{
Ana Cláudia Carvalho de Miranda \\ Mestra em Administração \\ Universidade Federal do Rio Grande do Norte \\ Bibliotecária e Documentalista \\ Escola da Magistratura do Rio Grande do Norte \\ anaclaudia.biblio@gmail.com
}

\begin{abstract}
Resumo
Este artigo se propõe a apresentar um aporte teórico sobre bibliotecas especializadas e desenvolvimento de coleções a fim de fornecer subsídios para o estabelecimento de diretrizes e normas que servirão de base para o planejamento das ações a serem tomadas na gestão de coleções. Como metodologia, utiliza-se a pesquisa bibliográfica com uso de informações em fontes de informação heterogêneas, tais como: periódicos, livros, websites, anais, entre outros. O estudo revelou a importância da política de desenvolvimento e formação do acervo como parâmetro para auxiliar o bibliotecário na tomada de decisões, nas etapas do processo de desenvolvimento de coleções. Constatou-se, também, que a formação do acervo com qualidade está condicionada à flexibilidade para ajustar a política de desenvolvimento de coleções, sempre que for constatado que a biblioteca não está atendendo aos reais interesses dos seus usuários.
\end{abstract}

\section{Palavras-chave}

Biblioteca especializada. Gestão de coleção. Formação e desenvolvimento de coleções. Política de desenvolvimento de coleções.

\section{INTRODUÇÃO}

Nas últimas décadas, a informação tem sido considerada uma ferramenta importante para os diversos campos do conhecimento; organizá-la e administrá-la não é tarefa simples, pois requer planejamento e diretrizes bem definidas para atender às necessidades informacionais dos usuários das unidades de informação.

No entanto, as bibliotecas, principalmente as especializadas, necessitam de inovação constante para a melhoria na gestão de coleções. Uma vez que na sociedade da informação, o conhecimento é renovado aceleradamente, ocasionando, assim, uma maior dificuldade para que as bibliotecas mantenham suas publicações sempre atualizadas, torna-se, imprescindível, a elaboração de políticas de atualização e expansão dos acervos voltados para o perfil dos usuários.

Diante dessa realidade, um gerenciamento bem-feito do acervo é fator fundamental à plena consecução dos objetivos das bibliotecas. A formação, desenvolvimento e organização da coleção devem ser encarados como um processo permanente no qual as atividades de seleção, aquisição e avaliação de materiais permaneçam em contínua sintonia com as necessidades de informação da comunidade de usuários. Contudo, as bibliotecas especializadas devem atender às necessidades de informação das organizações ou empresas nas quais estão inseridas. 
Cabe ao bibliotecário que exerce suas atribuições numa biblioteca especializada promover melhorias, com criatividade, para reconhecer as oportunidades de transformar ideias em soluções. No que concerne às soluções, estas são entendidas como ações específicas, as quais devem ser organizadas de forma que possam ser implementadas e acompanhadas por todas as pessoas envolvidas no processo de gestão de coleção.

Constata-se, portanto, que, apesar da importância das bibliotecas especializadas para o desenvolvimento das organizações, há dificuldade de se encontrar estudos na literatura nacional que esclareçam sobre a conceituação e dinâmica das unidades de informação especializadas.

Diante desse cenário, o objetivo deste artigo é apresentar um estudo teórico referente ao desenvolvimento de coleções nas bibliotecas especializadas com foco no estabelecimento de diretrizes para elaboração de uma política que dê suporte aos bibliotecários, assessorando-os na execução dessa atividade. Nesse sentido, são apresentados, a seguir, conceitos e ponderações sobre bibliotecas especializadas, com ênfase na formação e desenvolvimento do acervo, salientando as instruções para melhor conexão entre os recursos informacionais e a comunidade a ser servida.

\section{METODOLOGIA}

O presente trabalho apresenta uma pesquisa qualitativa, de caráter exploratório, utilizando como procedimento metodológico a pesquisa bibliográfica para coleta de dados com base na literatura da Ciência da Informação, em especial, voltados para os seguintes assuntos: bibliotecas especializadas, formação e desenvolvimento de coleções, gestão de coleções e política de desenvolvimento de coleções.

No entendimento de Gil (2008), a pesquisa bibliográfica, apontada como primeiro passo para a revisão de conceitos, constitui-se como base de qualquer pesquisa científica. Segundo Boaventura (2012), o processo de revisão de literatura analisa a produção bibliográfica dentro de uma temática, em um recorte de tempo, fornecendo um panorama geral, a fim de estabelecer as linhas de ação para abordar o assunto ou problema e gerar novas ideias úteis. Marconi e Lakatos (2010) apontam que a pesquisa bibliográfica busca levantar toda bibliografia já publicada em forma de artigos em revistas e sites, teses, dissertações, livros, publicações avulsas e na imprensa escrita ou on-line.

Sendo assim, esse tipo de pesquisa assegura ao pesquisador acesso à literatura escrita sobre determinado assunto, com a finalidade de se estabelecer um panorama dos assuntos abordados, possibilitando apontar as possíveis convergências e divergências entre conceitos. Portanto, sob o ponto de vista dos autores, permite-se analisar criticamente o assunto e perceber como o fenômeno tem sido descrito em variados contextos.

A fim de atingir o objetivo proposto para este estudo, utilizaram-se livros, dissertações, artigos científicos, websites e anais de eventos sobre os temas abordados, de modo a reunir dados dispersos, buscando a apropriação de informações sobre os conceitos abordados.

\section{BIBLIOTECA ESPECIALIZADAS}

O avanço da imprensa desencadeou um fluxo maior de circulação de informações, possibilitando um crescimento na produção dos livros. Segundo Milanesi (1983), a quantidade e diversidade de publicações se expandiram devido a muita informação disponível, gerando um descontrole. Tal fato colaborou para o surgimento das bibliotecas especializadas

Historicamente, as bibliotecas especializadas surgiram no início do século XX, especialmente em razão do grande avanço científico e tecnológico e, consequentemente, do crescimento informacional. Depois da Segunda Guerra Mundial, elas tiveram seu período de maior expansão e permanecem se propagando até a época atual (FIGUEIREDO, 1979).

Atualmente, as bibliotecas especializadas se originam da necessidade de órgãos governamentais, universidades (bibliotecas setoriais) ou empresas (industriais ou comer- 
ciais), atuando como importantes agentes disseminadores dos conhecimentos necessários aos estudos e tomadas de decisões das instituições das quais fazem parte.

Esses tipos de bibliotecas são formados por coleções que buscam atender aos objetivos das organizações nas quais se encontram inseridas. Nessa linha, Volpato (1999, p. 44) aborda, de maneira especial, em sua dissertação de mestrado, que "quanto mais especializada a biblioteca, mais claros são suas metas e objetivos", ou seja, propicia ao usuário a informação de que necessita, no assunto que procura. Nesse contexto, Figueiredo (1979, p. 10) destaca que essas bibliotecas:

Quadro 1 - Diferença entre as bibliotecas especializadas e as demais
Podem se localizar em organizações as mais diversas, a maioria pertencendo a companhias industriais; contudo, podem existir bibliotecas especializadas em agências do governo (ministérios, autarquias, empresas semi-estatais, instituições particulares de pesquisa, sociedades profissionais, associações de comércio, instituições acadêmicas com coleções departamentais, em bibliotecas públicas com coleções especializadas de assunto, e ainda, em hospitais, bancos, escritórios de engenharia e planejamento, de advocacia etc.).

\begin{tabular}{|c|c|}
\hline Autor & Diferença / Conceito \\
\hline Ashworth (1967, p. 632) & $\begin{array}{l}\text { "A biblioteca especializada é uma biblioteca quase exclusivamente dedicada a } \\
\text { publicações sobre um assunto ou sobre um grupo de assuntos em particular. } \\
\text { Inclui também coleções de uma espécie particular de documentos." }\end{array}$ \\
\hline Wright (1967, p. 1) & $\begin{array}{l}\text { "Biblioteca especializada significa uma biblioteca quase exclusivamente } \\
\text { dedicada a publicações sobre um assunto ou um grupo de assuntos em } \\
\text { particular." }\end{array}$ \\
\hline Cezarino $(1978$, p. 238$)$ & $\begin{array}{l}\text { "As bibliotecas especializadas são unidades pertencentes a instituições } \\
\text { governamentais, particulares ou associações formalmente organizadas com o } \\
\text { objetivo de fornecer ao usuário a informação relevante de que ele necessita, } \\
\text { em um campo específico de assunto." }\end{array}$ \\
\hline Figueiredo (1978) & $\begin{array}{l}\text { "Distinguem-se das demais, principalmente em relação ao acervo bastante } \\
\text { diversificado, à manutenção de acervo relativamente pequeno, porém } \\
\text { atualizado, e à necessidade de forte intercâmbio com outras bibliotecas, } \\
\text { visando suprir sua possível deficiência de material." }\end{array}$ \\
\hline Targino (1988) & $\begin{array}{l}\text { "A biblioteca especializada é aquela que tem um acervo composto de } \\
\text { material bibliográfico técnico destinado a atender os campos de atuação de } \\
\text { uma determinada instituição." }\end{array}$ \\
\hline Maia et al. (1991, p. 688) & $\begin{array}{l}\text { "A biblioteca especializada deve como vista sempre como centro de suporte } \\
\text { da informação, os quais podem ser locais de suporte à informação, } \\
\text { cumprindo seu papel e ocupando o seu espaço na cadeia de inovação } \\
\text { tecnológica". }\end{array}$ \\
\hline Dias e Pires (2003) & $\begin{array}{l}\text { "Biblioteca especializada é um centro de informação, formado por acervo } \\
\text { específico e voltado prioritariamente para o campo do conhecimento, em } \\
\text { conformidade com os interesses da organização." }\end{array}$ \\
\hline Miranda $(2007$, p. 88$)$ & $\begin{array}{l}\text { "As bibliotecas especializadas são constituídas por acervo que visa suprir as } \\
\text { necessidades da organização à qual se encontram inseridas, apesar de incluir } \\
\text { sempre um certo número de obras sobre áreas afins ou relacionadas." }\end{array}$ \\
\hline
\end{tabular}

Fonte: Autora (2018).

As bibliotecas especializadas possuem uma função fundamental nesse processo, uma vez que são responsáveis pela coleta, organização, gerenciamento, preservação e, sobretudo, pela difusão do conhecimento em seus variados formatos. De acordo com
Figueiredo (1978), esses tipos de bibliotecas poderão colaborar com a instituição da qual fazem parte de diversas formas, entre elas: no fornecimento de informações aos membros da organização, de modo rápido e econômico; na redução dos custos de operação 
relacionados à duplicação de esforços de pesquisa e na eliminação do tempo de pesquisar em outras instituições a informação desejada.

$\mathrm{Na}$ maioria das bibliotecas especializadas, as publicações periódicas são de primordial importância, constatando-se também a existência de relatórios, folhetos, normas, monografias, teses, obras de referências especializadas, maquetes, croquis, slides, projetos, fotos, bases de dados, DVDs e outros materiais publicados em separata, que são armazenados em quantidade significativa, exigindo-se dos bibliotecários dedicação e empenho para localização e obtenção dos itens solicitados pelos usuários. No que tange às diferenças entre as bibliotecas especializadas e as demais, estas serão apresentadas, no Quadro 1.

Entre os diversos posicionamentos defendidos pelos autores (Quadro 1), fica claro que as bibliotecas especializadas necessitam de constante atualização e revisão do seu acervo e dos seus serviços. Sendo assim, elas têm como principal compromisso o atendimento das necessidades informacionais com foco voltado para o avanço e crescimento da organização ou dos seus usuários, com as informações em seu estágio mais atual, ou seja, o estado-da-arte na área de concentração do conhecimento específico. Para tanto, não lhes basta manter um acervo, mas precisam estar em constante ligação com bibliotecas congêneres, centros de documentação e redes de informação. Nesse sentido, as bibliotecas especializadas não podem estar isoladas; ao contrário, sua comunicação com outras fontes de informações e as atividades de intercâmbio são fundamentais para o exercício de seu papel na organização a que serve.

Nessa perspectiva, são apresentadas, no Quadro 2, as funções das bibliotecas especializadas e, no Quadro 3, suas características, a fim de demonstrar uma visão mais abrangente desses tipos de unidades de informação para servir de base na construção da política de desenvolvimento do acervo.

Quadro 2 - Funções das bibliotecas especializadas

\begin{tabular}{|c|c|}
\hline \multirow{7}{*}{ 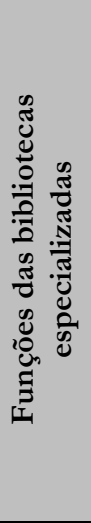 } & $\begin{array}{l}\text { Disponibilizar informação, de forma rápida e eficaz, centrada em uma área do conhecimento, } \\
\text { buscando atender às necessidades dos usuários. }\end{array}$ \\
\hline & Tratar, de forma exaustiva, os documentos, ampliando os recursos de recuperação da informação. \\
\hline & Atualizar, permanentemente, a coleção dos catálogos. \\
\hline & $\begin{array}{l}\text { Difundir, constantemente, a informação, por meio de boletins, e-mails, resumos, redes sociais, } \\
\text { entre outros. }\end{array}$ \\
\hline & $\begin{array}{l}\text { Disseminar, seletivamente, a informação em conformidade com as necessidades informacionais } \\
\text { do seu público. }\end{array}$ \\
\hline & Proporcionar acesso a bases de dados, conforme a temática e o nível de interesse dos usuários. \\
\hline & $\begin{array}{l}\text { Permitir recuperação aprofundada de informações sobre assuntos específicos e das áreas } \\
\text { correlatas. }\end{array}$ \\
\hline
\end{tabular}

Fonte: Autora (2018).

Quanto o perfil dos usuários das bibliotecas especializadas, Figueiredo (1978, p. 156) afirma que

[...] se distinguem também pelo tipo de pessoas de que são servidas: pessoas associadas às organizações mantenedoras e que têm interesses e habilidades especiais.
Portanto, diante de tudo o que foi explicitado, pode-se afirmar que, como fonte de conhecimento qualificado, as bibliotecas especializadas cumprem um papel estratégico para a moderna organização, pois lhes compete tornar acessível qualquer conhecimento ou experiência que possa ser coletada, contribuindo, assim, para o avanço dos trabalhos da organização e auxiliando no alcance dos seus objetivos. 
Gestão de coleções para bibliotecas especializadas:

uma perspectiva teórica para o planejamento de recursos informacionais

Quadro 3 - Características das bibliotecas especializadas

\begin{tabular}{|c|c|}
\hline \multirow{7}{*}{ 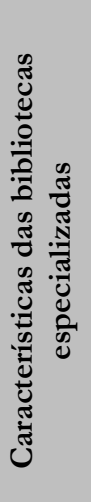 } & $\begin{array}{l}\text { Tipologia e tratamento da documentação mais seletiva, conforme a área de interesse da } \\
\text { organização a qual está inserida a biblioteca. }\end{array}$ \\
\hline & Usuários: possuem uma formação acima da média numa determinada área de conhecimento. \\
\hline & Bibliotecários devem possuir conhecimento na área a que se destina a coleção. \\
\hline & Acervo composto por diferentes de suportes informacionais. \\
\hline & Interação contínua com outras bibliotecas e centros de informação da mesma especialidade. \\
\hline & $\begin{array}{l}\text { Alto nível de automação dos serviços, a fim de possibilitar uma melhor recuperação da } \\
\text { informação. }\end{array}$ \\
\hline & Dimensão menor que as demais congêneres em termos de espaço, coleção e recursos humanos. \\
\hline
\end{tabular}

Fonte: Autora (2018).

Diante desse cenário - na Era do Conbecimento -, percebe-se que as bibliotecas especializadas atuam como importantes disseminadores do uso da informação para os membros das organizações. De acordo com Miranda (2017), estas, por sua vez, originaram-se da necessidade informacional dos órgãos governamentais, universidades (bibliotecas setoriais), escritórios de advocacia, empresas (industriais ou comerciais), para subsidiarem e respaldarem nas decisões em fluxo. Portanto, faz-se necessário que as bibliotecas desenvolvam um planejamento para formação e desenvolvimento de suas coleções visando à satisfação de seu público específico.

\section{DESENVOLVIMENTO DE COLE- ÇÕES}

O termo desenvolvimento de coleções compreende o planejamento e o desenvolvimento sistemático da coleção existente, englobando, ocasionalmente, a seleção e a aquisição de materiais para o acervo da biblioteca. A esse respeito, Klaes (1991, p. 31) pondera que

O desenvolvimento de coleções constitui uma das atividades mais importantes, na medida em que dela depende a provisão dos recursos informacionais $\mathrm{da}$ biblioteca $[\ldots]$.
Para Evans (1979), há relevância por ser um processo de identificação dos pontos fortes e fracos do acervo da biblioteca em termos de necessidades informacionais dos usuários, sendo identificadas mediante avaliações contínuas das fontes da biblioteca, bem como por meio de estudos relacionados com as necessidades dos usuários e das mudanças dos interesses das organizações.

Além desses autores, Wortman (1989) afirma que o desenvolvimento de coleções descreve todas as atividades de seleção, aquisição e manutenção de coleções em uso. Por isso, essas atividades precisam ser tratadas como partes inter-relacionadas de um complexo programa de gestão de coleções.

Segundo Baughman (1977 apud VERGUEIRO 1993, p. 15):

O desenvolvimento de coleções deve ser entendido sob o ponto de vista estruturalista, significando, com isso, "a procura de um padrão de relacionamento" entre as partes integrantes nesta atividade bibliotecária.

Diante desse contexto, o desenvolvimento de coleções é composto de três itens, a saber:

a) Uso: grupo de demandas.

b) Conhecimento: grupo de disci-plinas, assuntos, tópicos e áreas de estudo.

c) Biblioteconomia: grupo de relações entre as literaturas dos diversos assuntos. 
O modelo estruturalista, com foco no desenvolvimento de coleções, apresentado por Baughman (1977) e explanado por Vergueiro (1993, p. 16), é composto por três elementos:

a) Planejamento: projeto para acumulação de documentos afins, da maneira determinada pelas necessidades, propósitos, objetivos e prioridades da biblioteca.

b) Implementação: processo de tornar os documentos acessíveis para o uso.

c) Avaliação: exame e julgamento em relação aos objetivos e propósitos estipulados.

(1977) destaca, por fim, que o entrelaçamento desses conceitos em uma política para desenvolvimento de coleções conduz a um sistema que é cíclico e autoaperfeiçoável, conforme demonstrado na Figura 1.

Figura 1 - Desenvolvimento de coleções - abordagem estruturalista

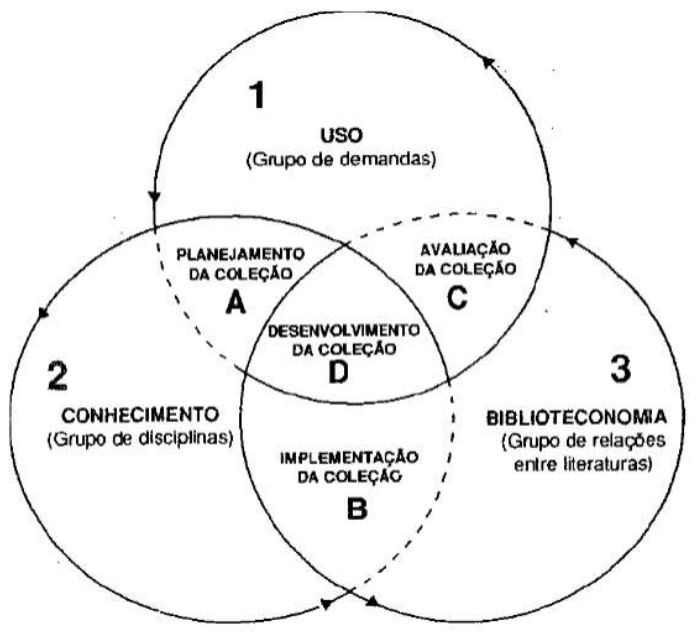

Fonte: Baughman (1977, p. 243).

Já o modelo do processo de desenvolvimento de coleções, idealizado por Evans, diverge do modelo de Baughman. Na perspectiva de Vergueiro, (1993, p. 17), o modelo de Baughman é considerado bastante elucidativo por apresentar esse processo de forma cíclica, ou seja, nenhuma etapa se sobrepõe às demais. Sendo assim, todas as etapas encontram-se no mesmo patamar de igualdade e giram, teoricamente, em torno de um pequeno círculo em que estão instalados os profissionais envolvidos com as atividades inerentes ao desenvolvimento de coleções. No círculo maior em torno desses componentes, encontra-se a comunidade de usuários da biblioteca, conforme Figura 2.

Figura 2 - Processo de desenvolvimento de coleções - abordagem sistêmica

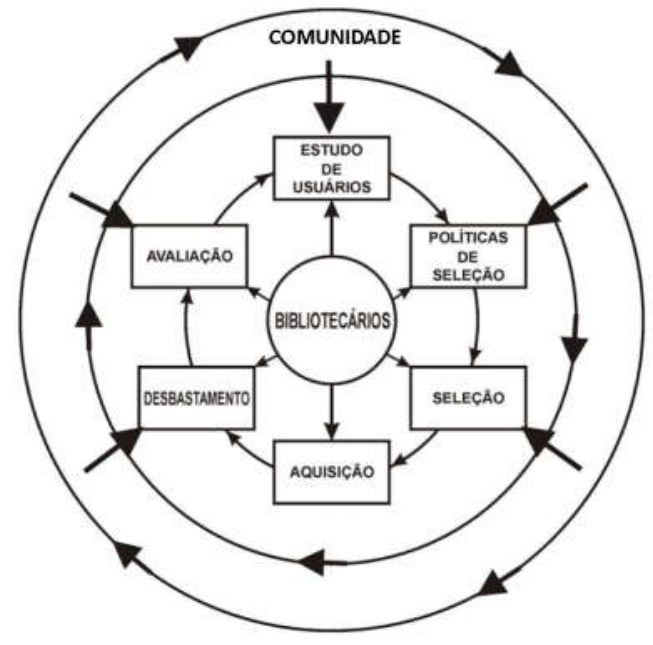

Fonte: Evans (1979).

Diante desse contexto, observa-se que a abordagem sistêmica, atribuída ao desenvolvimento de coleções, ganha características adicionais relevantes no tocante ao processo e à política, ou seja, o processo é considerado como cíclico e contínuo por Evans (1979), Vergueiro (1989) e Weitzel (2013). Contudo, esse processo é ininterrupto, tendo necessariamente de transformar-se em atividade rotineira das bibliotecas, garantia única de sua efetividade.

Assim, o desenvolvimento de coleções é um processo que não ocorre de maneira aleatória; abrange, portanto, seis etapas interdependentes. No entendimento de Evans (1979), essas fases envolvem estudo de comunidade, política de seleção, seleção, aquisição, desbastamento e avalição da coleção. Essas etapas estão presentes nas atividades rotineiras das bibliotecas, mesmo não acontecendo da mesma forma em todas elas. 
De acordo com Vergueiro (1989), o processo de desenvolvimento de coleções (descrito na Figura 2) é considerado um processo heterogêneo, tendo em vista que se apresenta da mesma forma em todos os tipos de bibliotecas, sem excluir ou acrescentar nenhuma etapa. Em outras palavras, o processo apresenta-se de modo específico, por meio do tipo, missão e função de cada unidade de informação.

Em geral, o acervo das bibliotecas é formado por livros, periódicos, panfletos, relatórios, manuscritos, filmes cinematográficos ou gravações de vídeo, gravações de som, artefatos tridimensionais, arquivos de dados legíveis por máquina, materiais cartográficos e iconográficos, música, etc. Potencialmente, qualquer objeto que comunique ou exprima informação, opinião ou sensação pode ser incluído em uma coleção de biblioteca. (EVANS, 1979). Portanto, é fundamental admitir a importância do desenvolvimento de coleções no processo de planejamento para a formação, seleção, aquisição e avaliação da coleção, com vistas à tomada de decisão na biblioteca.

Em decorrência das reflexões apresentadas, ressalta-se a necessidade de um plano que esteja fundamentado e em conformidade com as necessidades informacionais da organização à qual a biblioteca está subordinada, a fim de facilitar e garantir um excelente processo de desenvolvimento de coleção. Contudo, de acordo com Miranda (2007), é imprescindível a elaboração de um documento administrativo oficializado pelos dirigentes da organização intitulado política de desenvolvimento de coleções para respaldar a tomada de decisão na gestão do acervo.

\section{POLÍTICA DE DESENVOLVIMEN- TO DE COLEÇÕES}

Esse documento é bastante criterioso e imprescindível para nortear a tomada de decisão quanto à formação e crescimento do acervo bibliográfico, por meio do estabelecimento de normas que orientam as seguintes ações: seleção, aquisição, avaliação e des- bastamento. Por esse viés, Vergueiro (1989) destaca a política de desenvolvimento de coleções como um parâmetro que auxilia na tomada de decisão por parte dos bibliotecários. Acrescenta, ainda, que o referido documento visa propor balizas em relação à escolha do material a ser incorporado ao acervo e subsidiar a administração dos recursos informacionais. Por essa razão, a política de desenvolvimento de coleções deve fornecer aos bibliotecários subsídios para que estes argumentem com as autoridades superiores tanto para a liberação de novas aquisições como para recusas incoerentes.

A política precisa caminhar em sintonia com a missão e os objetivos da instituição na qual a biblioteca está inserida. A esse respeito, Weitzel (2013, p. 4) enfatiza que "[...] a missão, os objetivos e metas da biblioteca estarão em consonância com a missão, objetivos e metas da instituição mantenedora".

Segundo Vergueiro (1989), para elaboração da política de desenvolvimento de coleções, torna-se imprescindível realizar um diagnóstico com as seguintes informações: o estado atual da coleção (quais áreas em conformidade com a especialidade da biblioteca encontram-se inadequadas, necessitando de novas aquisições e quais áreas encontram-se eficientes para atender à demanda) e as necessidades informacionais da comunidade a ser servida.

A necessidade de se formalizar uma política de desenvolvimento de coleções tem como propósitos: impedir que o acervo se transforme num aglomerado inadequado de documentos e permitir a manutenção dos critérios, bem como orientar os profissionais responsáveis pelas decisões, auxiliando-os nos momentos em que o bibliotecário deve decidir entre um item ou outro. Nesse sentido, conforme exposto por Miranda (2007, p. 7), a política proporcionará

[...] uma exposição do estado geral da coleção, demonstrando o método para alcançar os objetivos e dar subsídios para os bibliotecários argumentarem com as autoridades superiores, tanto para a liberação 
de novas aquisições como para recusas incoerentes.

O Quadro 4 indica os fundamentos essenciais para a formulação de uma política de desenvolvimento de coleções. $\mathrm{Na}$ literatura sobre o assunto, Miranda (2007) salienta que, antes do processo de construção da política, é preciso determinar alguns procedimentos, com a finalidade de obter as metas e objetivos da política, sendo primordial apreciar os seguintes passos: a) identificação da missão e objetivos institucionais; b) perfil da comunidade; c) perfil das coleções; d) descrição das áreas e formatos cobertos pela biblioteca; e) descrição das etapas de processo de desenvolvimento de coleções; f) detalhamento de outros aspectos importantes; g) documentos correlatos; h) desfazimento dos documentos e i) avaliação da política. Nessa perspectiva, Weitzel (2006) enfatiza a importância dessa política por ser um instrumento necessário para garantir a consistência e permanência do processo de desenvolvimento de coleções em uma biblioteca.

Quadro 4 - Fundamentos norteadores da Política de Desenvolvimento de Coleções

\begin{tabular}{|c|c|}
\hline \multirow{10}{*}{ 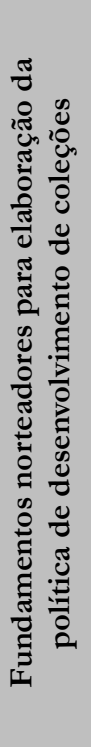 } & $\begin{array}{l}\text { Contribuir para um crescimento racional e equilibrado da coleção de forma qualitativa e } \\
\text { quantitativa. }\end{array}$ \\
\hline & Assegurar a continuidade e a adequação necessárias à formação da coleção. \\
\hline & Estabelecer os critérios para seleção e aquisição (compra, doação e permuta). \\
\hline & Estipular os critérios para duplicação de títulos. \\
\hline & Determinar as prioridades de aquisição de material. \\
\hline & $\begin{array}{l}\text { Conhecer as necessidades dos usuários, através de estudo de usuários e da análise de uso das } \\
\text { coleções. }\end{array}$ \\
\hline & Estabelecer critérios para intercâmbio de materiais informacionais. \\
\hline & $\begin{array}{l}\text { Acompanhar o surgimento dos novos suportes de informação, não se limitando apenas ao } \\
\text { suporte em papel. }\end{array}$ \\
\hline & $\begin{array}{l}\text { Buscar atender a todas as sugestões, deixando o solicitado informado da aquisição ou não do } \\
\text { item sugerido. }\end{array}$ \\
\hline & $\begin{array}{l}\text { Determinar os critérios para desfazimento/descarte de livros, folhetos, periódicos, material } \\
\text { não convencional e audiovisual. }\end{array}$ \\
\hline
\end{tabular}

Fonte: Adaptado de Miranda (2007).

É preciso constar no documento a indicação da responsabilidade nas decisões para a seleção da coleção, ou seja, se deve haver uma comissão. Romani e Borszcz (2006) recomendam que a comissão seja composta por:

a) um bibliotecário, responsável pela unidade de informação;

b) um representante das principais áreas de atuação (ou departamentos acadêmicos) da instituição à qual está diretamente subordinada;

c) um representante da área administrativa (setor de compras).
Concluída a elaboração das políticas, obtém-se um documento administrativo oficializado perante os dirigentes da instituição designado política de desenvolvimento de coleçoes, que deve ser revisado a cada dois anos pela comissão da biblioteca, com a finalidade de garantir sua adequação à comunidade e aos objetivos da instituição. Portanto, segundo Miranda (2017), a política de desenvolvimento de coleções é um documento que estabelece critérios e diretrizes para garantir a qualidade e a credibilidade da coleção no tocante à tomada de decisão relacionada com a incorporação, ou a retirada definitiva de materiais pertencentes ao acervo. 


\section{CONSIDERAÇÕES FINAIS}

Este trabalho partiu da motivação de produzir mais conhecimento sobre as bibliotecas especializadas no contexto da política de desenvolvimento de coleções, a fim de expor os passos para elaboração desse documento, buscando agilizar os procedimentos necessários para atender às necessidades das instituições de que fazem parte.

A formação da coleção das bibliotecas especializadas possui um diferencial por ter uma quantidade superior de documentos não convencionais, exigindo-se dos bibliotecários maior empenho na busca, obtenção e processamento técnico desses materiais. Outra distinção se refere ao perfil dos seus usuários, que possuem um nível elevado de qualificação, tornando-os mais exigentes nas solicitações das suas pesquisas.

A abordagem sistêmica, proposta por Evans e atribuída ao desenvolvimento de coleções, é um processo considerado como cíclico e contínuo, abrangendo seis etapas, a saber: estudo de comunidade, política de seleção, seleção, aquisição, desbastamento e avalição da coleção, as quais auxiliam como parâmetro para o bibliotecário elaborar a política de desenvolvimento e formação de coleção.

A política servirá como uma ferramenta de planejamento para uniformizar o gerenciamento das coleções de modo que seu crescimento e expansão ocorram harmoniosamente, em todas as áreas do acervo, evitando-se seu crescimento desordenado, sem metas ou objetivos definidos. Dessa forma, Figueiredo (1999) adverte que a coleção precisa ser equilibrada, tomando-se por base os relatórios estatísticos coletados regularmente. Mediante esses relatórios - em que for constatado menor uso -, a coleção deverá ser incrementada a fim de melhorar sua oferta e exploração pelos usuários. Caso contrário, a coleção poderá ser mais fraca, de menos recursos, dada a pouca solicitação e o alto custo-benefício envolvido. Em se tratando de área do conhecimento sem demanda, não será preciso manter nenhuma coleção, pois estará demonstrada a completa inutilidade de se manterem os títulos relacionados à referida área.

Nessa direção, constatou-se que, para um efetivo alcance dos objetivos propostos na política de formação e desenvolvimento de coleções, é preciso estar atrelada aos recursos financeiros disponíveis à aquisição de material bibliográfico e não convencional. Além disso, a qualidade do acervo está condicionada à flexibilidade para modificar ou ajustar a política de desenvolvimento de coleções, sempre que for constatado que a biblioteca não está atendendo aos reais interesses dos seus usuários.

Portanto, sugere-se que estudos futuros possam abordar novas discussões e relatar experiências, intensificando o conteúdo na esfera da política de desenvolvimento de coleções, no panorama das bibliotecas especializadas.

\title{
COLLECTION MANAGEMENT FOR SPECIALIZED LIBRARIES: A theoretical perspective for the informational resources planning
}

\begin{abstract}
This article proposes to present a theoretical contribution on libraries and development of collections in order to provide establishing guidelines and standards that will serve as a basis for the planning of actions to be implemented in the management of collections. As a methodology, the bibliographical research using information in beterogeneous sources of information, such as: periodicals, books, websites, annals, among others. The study importance of development policy and the formation of the acquis as a parameter for assist the librarian in the decisions making, in the stages of the development of collections. It was also found that the quality is conditioned by the flexibility to collections development policy, provided that it is established that the library is not meeting the real interests of its users.
\end{abstract}

Keywords

Specialized library. Collection management. Formation and development of collections. Collection Development Policy. 
Artigo recebido em 12/06/2018 e aceito para publicação em 20/08/2018

\section{REFERÊNCIAS}

ASHWORTH, W. Manual de bibliotecas especializadas e de serviços informativos. Lisboa: Calouste Gilbenkian, 1967.

BAUGHMAN, J. C. Toward a structural approach to collection development. College $\&$ Research Libraries, v. 38, n. 3, maio 1979, p. $241-248$.

BOAVENTURA, E. M. Metodologia da pesquisa: monografia, dissertação, tese. São Paulo: Atlas, 2012.

CEZARINO, M. A. N. Bibliotecas especializadas, centros de documentação, centros de análise da informação: apenas uma questão de terminologia? Revista da Escola de Biblioteconomia da UFMG, Belo Horizonte, v.7, n. 2, p. 218-241. set. 1978.

DIAS, M. M. K.; PIRES, D. Formação e desenvolvimento de serviços informacionais. São Carlos: EdUFSCar, 2003.

EVANS, E. G. Developing library collections. Littleton: Libraries Unlimited, 1979.

FIGUEIREDO, N. Bibliotecas universitárias e especializadas: paralelos e contrastes. Revista de Biblioteconomia de Brasília, Brasília, v. 7, n. 1, p. 9-25, jan./jun. 1979. Disponível em: $<$ http://basessibi.c3sl.ufpr.br/brapci/index. $\mathrm{php} /$ article/download/16855>. Acesso em: 03 jul. 2017.

Serviços oferecidos por bibliotecas especializadas: uma revisão da literatura. Revista Brasileira de Biblioteconomia e Documentação, São Paulo, v. 11, n. 3/4, p. 155-168, jul./dez. 1978.

GIL, A. C. Métodos e técnicas de pesquisa social. 6. ed. São Paulo: Atlas, 2008.

KLAES, R. R. Dados e informações usados na tomada de decisão em bibliotecas universitárias brasileiras: o contexto da atividade de desenvolvimento de coleções. 1991. 271 f. Dissertação (Mestrado em Biblioteconomia e Documentação) - Universidade de Brasília, Brasília, 1991.

MAIA, C. et al. Informação científica e tecnológica e desenvolvimento econômico e social: a contribuição da biblioteca especializada. In: CONGRESSO BRASILEIRO DE BIBLIOTECONOMIA E DOCUMENTAÇÃO, 16, Salvador. Anais... Salvador, 1991, v. 2, p. 683-691.

MARCONI, M. A.; LAKATOS, E. M. Fundamentos de metodologia científica. São Paulo: Atlas, 2010.

MILANESI, L. O que é biblioteca. São Paulo: Brasiliense, 1983. (Coleção Primeiros Passos, 94).

MIRANDA, A. C. C. Biblioteca jurídica: uma reflexão acerca da gestão do acervo. Folha de rosto: revista de Biblioteconomia e Ciência da Informação, Juazeiro do Norte, v.3, n.1, p41-55, jan./jun., 2017. Disponível em:

$<$ https://periodicos.ufca.edu.br/ojs/index.p $\mathrm{hp} /$ folhaderosto/article/view/185/148>.

Acesso em: 6 mar. 2018.

. Formação e desenvolvimento de coleções em bibliotecas especializadas. Informação \& sociedade: estudos, João Pessoa, v.17, n.1, p.87-94, jan./abr., 2007. Disponível em:

$<$ http://www.periodicos.ufpb.br/ojs/index. $\mathrm{php} /$ ies/article/view/463/1468>. Acesso em: 6 mar. 2018.

ROMANI, C.; BORSZCZ, I. (Orgs.). Unidades de informação: conceitos e competências. Florianópolis: Ed. da UFSC, 2006.

TARGINO, M. G. Bibliotecas Universitárias e especializadas de São Luís. Revista de Biblioteconomia de Brasília, v. 16, n. 1, p. 19-32, jan./jun. 1988. 
VERGUEIRO, W. C. S. Desenvolvimento de coleções. São Paulo: Polis, 1989. (Coleção Palavra-chave, 1).

Desenvolvimento de coleções: uma nova visão para o planejamento de recursos informacionais. Ciência da Informação, Brasília, v. 22, n. 11, p. 13-21. jan./abr. 1993.

VOLPATO, S. M. B. A trajetória de uma biblioteca especializada: o caso da biblioteca do curso de pós-graduação em Administração da UFSC. 1999. 140 f. Dissertação (Mestrado em Engenharia de Produção) Centro Tecnológico, Universidade Federal de Santa Catarina, Florianópolis, 1999.
WEITZEL, S. R. Elaboração de uma política de desenvolvimento de coleções em bibliotecas universitárias. 2. ed. Rio de Janeiro: Interciência; Niterói: Intertexto, 2013.

WIRGHT, J. E. A biblioteca especializada e o serviço informativo. In: ASWORTH, W. Manual de bibliotecas especializadas e de serviços informativos. Lisboa: Fundação Guben-kian, 1967.

WORTMAN, W. Collection Development: background and pricinples. Chicago: ALA, 1989. 